\title{
Impact of Covid-19 Coronavirus Spreading on Working Time Efficiency
}

\author{
Kipervar E.A. ${ }^{1}$ Pobiyanskaya A.V. ${ }^{1,{ }^{*}}$ Kipervar E.A. ${ }^{2}$ \\ ${ }^{1}$ Omsk State Technical University, Omsk, 644050, Russia, kipervar@list.ru \\ ${ }^{2}$ Higher School of Economics, Moscow 101000 Russia, kea2025@gmail.com \\ ${ }^{*}$ Corresponding author. Email: batueva-nastya@mail.ru
}

\begin{abstract}
The article discusses the impact of the coronovirus proliferation on the efficiency of working time use at modern enterprises. The urgency of article is defined by importance of increase of efficiency of use of working time at the enterprise. Effective activity of the enterprises is connected with digital technologies. Increasing the importance of digital technology in modern conditions of coronovirus distribution, due to increasing attention from the management of companies to the introduction of digital technology for the future development of enterprises. Thus, the use of digital technologies not only increases the efficiency of the enterprise, but also the ability of personnel to work in different operating modes. The use of digital technologies makes it possible to increase the competitiveness of enterprises in modern economic conditions.

The aim of the study is to analyse the impact of the spread of COVID-19 coronavirus on the efficiency of working time use, as well as to study the impact of the organisation on the efficiency of personnel work at remote workplaces.

To achieve this goal, the following tasks were set in the course of the study: to conduct a survey of the personnel of Omsk organisations in order to determine the advantages and disadvantages of remote operating modes; to identify the risks and obstacles to the introduction of digital technologies at enterprises in the conditions of the spread of the pandemic; to identify digital technologies for monitoring and recording the working hours of employees at remote operating modes.

As a result of the research, the advantages and disadvantages of remote operating modes were identified; a mechanism for evaluating working hours depending on the remote operating mode was developed; digital technologies used at Russian enterprises to monitor and record working hours were analysed; risks and obstacles in the use and implementation of digital technologies were identified; the effectiveness of digital technologies in modern enterprises was noted.

Keywords: pandemic, COVID-19 coronavirus, working hours, telecommuting, labour efficiency, productivity
\end{abstract}

\section{INTRODUCTION}

The global pandemic in 2020 has caused important social and economic consequences for all countries in the world. It has had a negative impact on the economy, a decrease in GDP and labour productivity, a decrease in people's income, the postponement or cancellation of sports competitions and cultural and political events. At the same time, the general COVID-19 pandemic was the driving force behind the dramatic development of digital technologies, and the question of transferring workers to remote work from home was sharply raised.

\section{METHODS}

As a result of the mass coronavirus pandemic, it became necessary to transfer Russian enterprises to both permanent and temporary operation, depending on the type of enterprise and its technical capabilities. However, the Labour Code of 30.12.2001 N 197-FZ (ed. 31.07.2020) only reflects the definition of "remote work", not affecting its possible types [1]. In this connection, deputies of the State Duma and members of the Federation Council have developed a draft law which introduces significant changes to the regulation of remote and remote work. This Federal Law introduces three types of remote (remote) work: permanent, temporary and combined [2].

Permanent remote work ("remote work") - Performing a work function defined by an employment contract outside the employer's location at its branch office of a representative office of another separate structural unit ( including territories or objects located in another location outside the stationary workplace that are directly or indirectly under the control of the employer, provided that they are used to perform this work function and to carry 
out interaction between the employer and the employee on issues related to its performance). [2].

Temporary remote work refers to the "temporary performance of an employee's work function outside a fixed place of work" [2]. Temporary remote work is the mode of work both at the workplace in the company office and remotely from home.

To prevent the spread of COVID-19, companies can independently organise the application of the modes of work presented, based on the more value to the organisation, taking into account the company's digital and technological capabilities.

\section{RESULTS}

The COVID-19 coronavirus pandemic affected all Russian cities, including Omsk.

The Centre for Strategic Research conducted a study of the impact of the COVID-19 Coronavirus pandemic on Russian companies' business. It was noted that $29 \%$ of companies have optimised their payroll: 'they have introduced remote work with lower pay, reduced staff and salaries, transferred some employees to contracts; $40 \%$ plan to make such decisions in the future; $13 \%$ intend to reduce the number of employees' [3].

According to the regional information agency OmskInform, in Omsk due to the coronavirus crisis 182 companies were unprofitable, the most affected were: manufacturing production - $36.5 \%$, trade - $23.1 \%$, construction $-14.6 \%$, transportation and storage $-12.5 \%$ [4].

Despite the fact that Russian companies are not ready for a sharp transition to self-isolation and home-based work processes, the number of organisations (372) in the Omsk region doubled, with profits increasing by $4.7 \%$ compared to the same period (January-May 2019).

The number of vacancies with remote work mode is rapidly increasing, in July 2020 it was 2.5 times higher, and the number of those wishing to work in such a mode is also increasing 6 times higher [4].

In this regard, the consequences of the pandemic are both positive aspects that direct business towards innovation and revision of possible operating regimes for companies and negative aspects that affect the overall socio-economic situation in the region and its individual companies.

As noted earlier, companies in the Omsk Region switched to a remote mode of operation due to the spread of coronavirus COVID-19.
A survey of 140 respondents was conducted to determine the possible advantages and disadvantages of using remote mode of operation at 6 enterprises in the city of Omsk. These companies have switched to remote (remote) mode of operation since the introduction of the self-isolation mode.

In the course of the survey it was found that "remote" contributed to increased involvement in the work process (14\%), which can be explained by the comfortable working environment for the employee and the lack of constant monitoring. At the same time, $9 \%$ of respondents said that the permanent remote work mode, which was established in April-May 2020, reduces productivity as there is no possibility of personal contact with the head of the division. Almost $63 \%$ of the personnel surveyed consider working conditions to be comfortable and efficient with the possibility of visiting the company's office once or twice a week. Approximately the same number of surveyed staff points to the risk of reducing possible career development and loss of professional competence, namely $16 \%$ and $11 \%$ respectively. Employees of the companies are also concerned about the risk of a reduction in wages due to switching to a remote mode $-18 \%$. However, almost all respondents $(82 \%)$ note an increase in the level of satisfaction with work, as there are opportunities for free time and control over it, which is mainly important for the employee, despite the possibility of a decrease in wages.

According to company managers, when working remotely, it is difficult to assess the use of an employee's working time and the appropriateness of his or her expenses, and there is also a decrease in the efficiency of personnel working with the switch to remote work.

By introducing a remote type of work at the enterprise, there are a number of problems associated with the loss of working time of an employee, both in terms of personal needs and to solve working issues.

On the other hand, remote work can help to reduce unregulated losses of working time, namely: working late, as the employee does not depend on the speed of transport or possible contingencies; working time losses for breaks and conversations with colleagues are reduced.

In today's environment, a mechanism is needed to select a remote work mode, as well as to assess the use of working time and staff efficiency, so the initial option can be presented in Figure 1. 
Table 1 Advantages and disadvantages of remote (remote) modes of operation

\begin{tabular}{|c|c|c|c|c|c|}
\hline \multirow{2}{*}{ 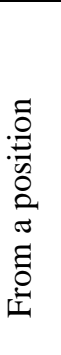 } & \multirow{2}{*}{ 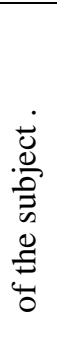 } & \multirow[b]{2}{*}{ Критерий } & \multicolumn{3}{|c|}{$\begin{array}{c}\text { Дистанционный } \\
\text { (удаленный) режим } \\
\text { работы }\end{array}$} \\
\hline & & & 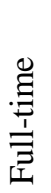 & 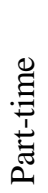 & $\begin{array}{l}\stackrel{D}{\otimes} \\
\stackrel{x}{\Sigma}\end{array}$ \\
\hline & \multirow{8}{*}{ 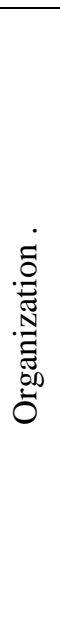 } & Reduced costs, savings on space rental & + & - & - \\
\hline & & Increased need for coordination & + & + & - \\
\hline & & Low communication with staff & + & + & - \\
\hline & & Costs of technology and equipment for workplaces at home & + & + & + \\
\hline & & Saves time, on delays due to vehicles & + & + & + \\
\hline & & $\begin{array}{l}\text { Possibility to hire highly qualified specialists with disabilities for } \\
\text { whom the Company is unable to organize the necessary working } \\
\text { conditions }\end{array}$ & + & - & - \\
\hline & & Company data leaks, their security is low & + & + & + \\
\hline & & Difficulty in recording working hours and non-productive costs & + & + & + \\
\hline \multirow{9}{*}{\multicolumn{2}{|c|}{ 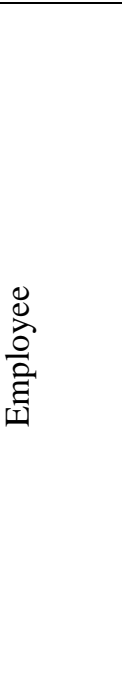 }} & Social isolation & + & + & - \\
\hline & & Reduced career opportunities & + & - & - \\
\hline & & Possible loss of professional competence & + & + & - \\
\hline & & Work time losses caused by household tasks & + & + & + \\
\hline & & No separation between family and work & + & + & + \\
\hline & & High level of involvement in the work & + & + & + \\
\hline & & $\begin{array}{l}\text { Increased independence of the employee and his level of organisation } \\
\text { of work }\end{array}$ & + & + & + \\
\hline & & $\begin{array}{l}\text { Increased job satisfaction from having free time and the ability to } \\
\text { control it }\end{array}$ & + & - & + \\
\hline & & Risk of salary reduction & + & + & + \\
\hline
\end{tabular}

* Developed by the authors 


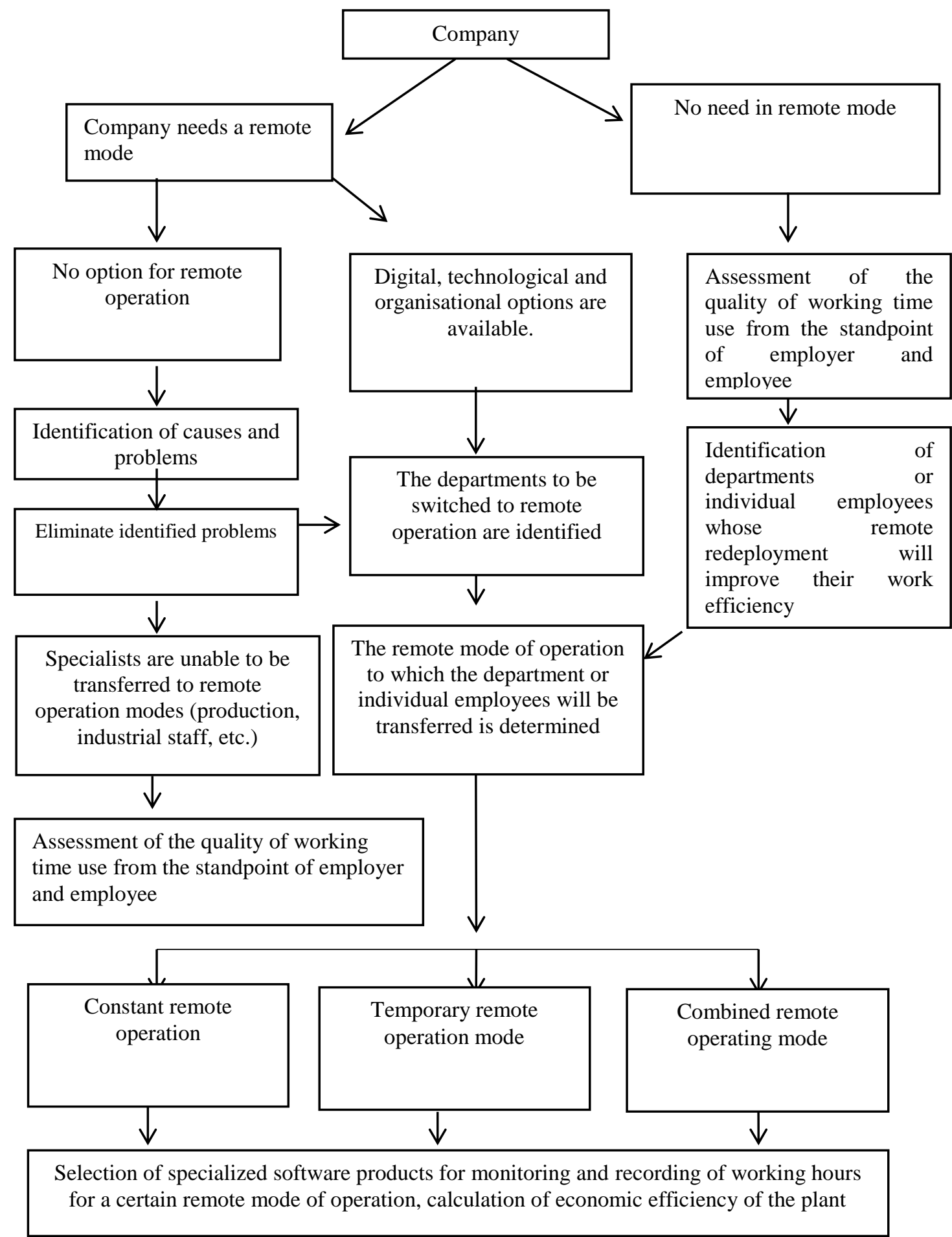

Installation of digital time recording and control products at remote workplaces

\section{$\downarrow$}

Evaluation of working time use based on an analysis of quantitative and qualitative performance indicators.

Fig. 1. Mechanism for evaluating the working time approach depending on remote (remote) mode of operation 
The conditions that have arisen in connection with a major pandemic have put companies in a position to choose a remote mode of operation, but the question of whether this transfer is possible and necessary is paramount.

The technological equipment and organisational capability of the company must be determined, and if translation is not possible, the causes and problems must be identified and addressed. As a result of choosing the remote work mode, the approach to assessing and recording time use will differ from the standard models. The main focus should not be on calculating the time lost through the employee's fault for minor distractions in the work process, but on increasing the quantitative and qualitative performance of the employee's work.

Not every organisation needs a remote work mode. Continuous production companies with special safety rules, two or three shift work schedules, raising the issue of transferring even individual employees to a remote work mode, must first assess the quality of working time use from the standpoint of employees and employers, work efficiency indicators, and after a complete analysis to determine the feasibility of transferring employees to a "remote" work mode.

Switching to a remote work mode is not capable of ensuring a high level of productivity and efficiency without the introduction of digital products that are carefully designed and aimed at full control of all working time costs.

In this situation, companies need to pay attention to the technical component and adjust their main work processes. Currently, there is a large number of different products and software aimed at controlling the work of personnel, their productivity and efficiency in the use of working time, including in remote working mode.

At the beginning of 2020, in Russia, in connection with the transition of enterprises to "remote operation", companies engaged in the development of software solutions, in a fairly short period of time, offered to the market technological solutions to monitor and record the working time of employees on a remote basis.

Thus, at the end of May 2020, Artezio presented its software product ART-Ping. According to the developers, this technical solution contributes to effective control of personnel working remotely. Managers will know whether the remote employee performs the assigned work at the computer, how focused he is on the tasks and whether it is necessary to pay attention to his productivity [5].

The REWTAS (Remote Employee Working Time Accounting System) programme is of interest to managers who aim to transfer employees to remote work mode. This product is aimed at accounting and control of working time of the personnel, analysis of productivity of its work and actual labour input, thus the presented product carries out forecasting of time of performance of tasks by the employee that is actual for heads [6].

The average cost in the Russian market varies from 400 to 1200 thousand roubles for one workplace that is feasible for the enterprises aimed at preservation of business. Emphasis should be placed not on total cost savings, but on the introduction of modern digital solutions and products aimed at increasing staff efficiency and productivity. The coronovirus pandemic has shown the existing social and economic problems and, at the same time, has opened up opportunities for reviewing business and the country's economy in general.

\section{DISCUSSION}

The COVID-19 pandemic has prompted a review of the working time category, its analysis, feasibility and evaluation of its use. Perhaps the focus should now be on flexible use of working time, the introduction of annual accounts, and the use of a rolling work schedule with mandatory remote attendance. By using "annual accounts" it is possible to reduce downtime and loss of working time due to organisational reasons, which contributes to the growth of productivity of employees at enterprises. If an employee's work has been completed in full and with proper quality in a shorter time than the length of the working day, there is no need to locate the employee at the workplace (including remote work). Unused working time is carried over to other intervals of the working period when a greater workload is required from the employee, in which case the need for overtime is also reduced, which has a negative impact on his ability to work.

The use of a rolling work schedule overlaps with the time of mandatory presence. In this case, the employee is provided with mandatory hours during which he or she must be at work and the rest of the time is planned independently. This method has its significance for young people, making it possible to combine training at a vocational institution with work, for pregnant women and women with children under 6 years of age, which will allow more time for the child and the necessary work to be done at home, and for workers over 50 years of age and over 20 years of experience. Employees at this age are the most qualified in their field, the replacement of young employees is inappropriate and will be accompanied by a loss of time, therefore it is possible to use this method, assigning these employees the most important and responsible work.

For personnel whose work cannot be transferred to a remote mode or the use of flexible working hours, it is possible to talk about shorter working hours, provided that they are efficient in their work and the quality of their work time use. In this way, it is possible to increase satisfaction with the work of the personnel and also increase the attractiveness of this work.

Often, company managers have a negative attitude towards remote and flexible working hours, which is justified by the reduction in productivity and the inability to keep records of working hours. With regard to the latter, it should be noted that on the basis of part 4 of Article 91 of the Labour Code, each enterprise is obliged to keep records of working hours of its personnel, regardless of how the employee's work is carried out in the company's office, remotely, on the road or otherwise. Regardless of the manner in which the work is carried out, the procedure for recording working hours must be set out in the 
regulations and local acts of the company [7]. In the digitalisation environment, the use of modern technological solutions can monitor the working time of employees with a travelling nature of work, and heads of departments and companies can analyse the factors that limit productivity growth.

\section{CONCLUSION}

In our opinion, further research is needed on the impact of distance working on staff efficiency, quality, and time management. In Russia, the use of a combined remote work mode may help to increase staff satisfaction, which will have a positive impact on efficiency and productivity. At the same time, remote work requires an objective analysis of working time use, and it is necessary to review existing approaches and develop evaluation mechanisms depending on the work mode.

\section{REFERENCES}

[1] Labour Code of the Russian Federation of 30.12.2001 №197-FZ (edition of 31.07.2020, as amended and supplemented, effective from 13.08.2020) // Consultant Plus Legal Reference System

[2] The project of the Federal law No. 973264-7 "About modification of the Labour code of the Russian Federation concerning regulation of remote and remote work" (ed., accepted GD FS RF in I reading 21.07.2020) // Reference-legal system "ConsultantPlus".

[3] How to set an employee's working time regime with flexible working hours. - 2020 // ConsultantPlus Legal Reference System. Due to the coronation crisis, the losses of Omsk companies increased by $41 \%$ [Electronic resource]. - Access mode: https://www.omskinform.ru/news/144472.

[5] Artezio ART-Ping / TAdviser. The State. Business. IT. [Electronic resource]. - Access mode: https://www.tadviser.ru/index.php/Продукт:Artezio_A RT-Ping.

[6] CorpSoft24 REWTAS Remote Employee Working Time Accounting System / TAdviser. State. Business. IT. [Electronic resource]. - Access mode: https://www.tadviser.ru/index.php/Продукт:CorpSoft2 4_REWTAS_(Remote_Employee_Working_Time_Acc ounting_System).

[7] Bazzhina, V.A.; Tsygankova, I.V.; Nikishina, O.Yu. Development of non-standard forms of employment in modern Russia (in Russian) // Russian
Entrepreneurship. - №24 (270). - 2014. [Electronic resource]. - Access mode: https://cyberleninka.ru/article/n/razvitie-nestandartnyhform-zanyatosti-v-sovremennoy-rossii.

[8] Semenova, Yu.E.; Ostrovskaya, E.N.; Khnykina, T.S. Problems of the enterprise remote work organization (in Russian) // Global scientific potential. 2020. - № 6 (111). - C. 174-176.

[9] Kosov I.A. Remote work and its peculiarities / Labour law. - 2020. - № 7. - C. 105-112.

[10] Shavrin, V.E. Impact of the Coronavirus Pandemic (COVID-19) on the Microfinance Sector of the Russian Economy / Innovative Science. - 2020. - № 7. - C. 3640 .

[11] Shestakova, E. According to the non-standard schedule. How to save on employees during the pandemic // Finansyaya Gazeta. - 2020. - №29. - C. 5 7. 